\title{
Continuous Exposure of Breast Cancer Cells to Tamoxifen Upregulates GPER-1 and Increases Cell Proliferation
}

\author{
Luis Molina ${ }^{1}$, Felipe Bustamante ${ }^{2,3}$, Alexander Ortloff ${ }^{4}$, Iraidi Ramos ${ }^{2,3}$, \\ Pamela Ehrenfeld ${ }^{2,3^{*}}$ and Carlos D. Figueroa ${ }^{2,3^{*}}$ \\ ${ }^{1}$ Facultad de Medicina y Ciencia, Universidad San Sebastián, Puerto Montt, Chile, ${ }^{2}$ Laboratory of Cellular Pathology, \\ Institute of Anatomy, Histology and Pathology, Universidad Austral de Chile, Valdivia, Chile, ${ }^{3}$ Centro Interdisciplinario de \\ Estudios del Sistema Nervioso (CISNe), Universidad Austral de Chile, Valdivia, Chile, ${ }^{4}$ Departamento de Ciencias Veterinarias \\ y Salud Pública, Facultad de Recursos Naturales, Universidad Católica de Temuco, Temuco, Chile
}

OPEN ACCESS

Edited by:

Marilena Kampa,

University of Crete, Greece

Reviewed by:

Stephen A. Whelan,

Boston University, United States

Guillermo Romero,

University of Pittsburgh, United States

${ }^{*}$ Correspondence:

Carlos D. Figueroa

cfiguero@uach.cl

Pamela Ehrenfeld

ingridehrenfeld@uach.cl;

pamelaehrenfeld74@gmail.com

Specialty section:

This article was submitted to

Molecular and Structural

Endocrinology,

a section of the journal

Frontiers in Endocrinology

Received: 18 May 2020 Accepted: 08 September 2020 Published: 30 September 2020

Citation:

Molina L, Bustamante F, Ortloff A, Ramos I, Ehrenfeld $P$ and Figueroa $C D$ (2020) Continuous Exposure of Breast Cancer Cells to Tamoxifen Upregulates GPER-1 and Increases Cell Proliferation.

Front. Endocrinol. 11:563165. doi: 10.3389/fendo.2020.563165
GPER-1 is a novel membrane sited G protein-coupled estrogen receptor. Clinical studies have shown that patients suffering an estrogen receptor $\alpha$ (ER $\alpha) / G P E R-1$ positive, breast cancer have a lower survival rate than those who have developed ER $\alpha$-positive/GPER-1 negative tumors. Moreover, absence of GPER-1 improves the prognosis of patients treated with tamoxifen, the most used selective estrogen receptor modulator to treat $E R \alpha$ positive breast cancer. MCF-7 breast cancer cells were continuously treated with 1,000 $\mathrm{nM}$ tamoxifen for 7 days to investigate its effect on GPER-1 protein expression, cell proliferation and intracellular $\left[\mathrm{Ca}^{2+}\right] i$ mobilization, a key signaling pathway. Breast cancer cells continuously treated with tamoxifen, exhibited a robust $\left[\mathrm{Ca}^{2+}\right] i$ mobilization after stimulation with 1,000 $\mathrm{nM}$ tamoxifen, a response that was blunted by preincubation of cells with G15, a commercial GPER-1 antagonist. Continuously treated cells also displayed a high $\left[\mathrm{Ca}^{2+}\right] i$ mobilization in response to a commercial GPER-1 agonist (G1) and to estrogen, in a magnitude that doubled the response observed in untreated cells and was almost completely abolished by G15. Proliferation of cells continuously treated with tamoxifen and stimulated with 2,000 nM tamoxifen, was also higher than that observed in untreated cells in a degree that was approximately $90 \%$ attributable to GPER-1. Finally, prolonged tamoxifen treatment did not increase ER $\alpha$ expression, but did overexpress the kinin B1 receptor, another GPCR, which we have previously shown is highly expressed in breast tumors and increases proliferation of breast cancer cells. Although we cannot fully extrapolate the results obtained in vitro to the patients, our results shed some light on the occurrence of drug resistance in breast cancer patients who are ER $\alpha /$ GPER-1 positive, have been treated with tamoxifen and display low survival rate. Overexpression of kinin B1 receptor may explain the increased proliferative response observed in breast tumors under continuous treatment with tamoxifen.

Keywords: GPER-1, GPR30, G1 agonist, calcium signaling, tamoxifen resistance, kinin B1 receptor, breast cancer, cell proliferation 


\section{INTRODUCTION}

Breast cancer is the most common type of cancer that produces high mortality in women, worldwide. In general, breast cancer is classified as estrogen receptor alpha $(\mathrm{ER} \alpha)$ positive or negative. ER $\alpha$-positive tumors comprise approximately $70 \%$ of all breast tumors and depend on estrogen to develop and grow $(1,2)$. It has been estimated that a large number of the responses mediated by $17 \beta$-estradiol, a kind of estrogen, occur through its binding to $\mathrm{ER} \alpha$, triggering a "genomic response" that initiates the transcription of genes associated to cell proliferation, survival and migration $(1,3)$. Nevertheless, estrogen also promotes a "rapid cellular response" (4), which includes an increase in intracellular calcium and activation of ERK1/2 mitogenactivated protein kinases (MAPKs), a signaling pathway that is considered crucial for cell proliferation $(5,6)$. Therefore, the efforts made so far to reduce breast cancer progress aim to suppress the synthesis of endogenous estrogen or to block ER $\alpha$, through the use of selective estrogen modulators (SERMs), among which tamoxifen stands out (3). However, the molecular heterogeneity of breast cancer, together with the existence of more aggressive forms of the disease and resistance to conventional drug therapy, suggest that other players may be involved in the pathogenesis and progress of this neoplasia.

G protein-coupled estrogen receptor-1 (GPER-1 or GPR30) is a $G$ protein-coupled receptor (GPCR) sited in the cell membrane that triggers a broad range of biological activities in response to stimulation by endogenous estrogens or dietary phytoestrogens $(2,7)$. Its gene is located on chromosome 7 p22.3 and encodes a protein of 375 amino acids with a theoretical molecular mass of $41 \mathrm{kDa}$ that is ubiquitously expressed in a large number of tissues (8-11). GPER-1 is highly expressed in the nervous and adipose tissues, liver and in the circulatory and immune systems among others. Its activation by $17 \beta$-estradiol has been corroborated by the use of labeled estradiol, and its synthetic agonist (G1) complemented with its pharmacological antagonist (G15) in normal and cancerous tissues and in various cell lines that do not express ER $\alpha(12,13)$. GPER-1 mRNA has been detected in several breast cancer cell lines and its expression has been associated with the increased proliferation rate exhibited by these cells. GPER-1 signaling involves cAMP production and $\mathrm{Ca}^{2+}$ mobilization most likely through protein Gos (13) and Src activation through $G \beta \gamma(14)$ and the subsequent shedding of heparin-binding EGF-like growth factor (HB-EGF) and transactivation of epidermal growth factor receptor (EGFR). GPER-1 induces also the activation of phospholipase $\mathrm{C}$ and cFos and various kinases such as ERK1/2 MAPK, phosphoinositide 3-kinase/protein kinase B (PI3K/Akt) $(6,15-$ 17). Evidence suggests that many of the responses attributed to ER $\alpha$ can be mediated, at least in part, by GPER-1. In fact, several of the beneficial responses produced by estrogens are absent in GPER-1 knockout mice $(18,19)$.

It has been shown that approximately $60 \%$ of all breast tumors are GPER-1-positive. In addition, expression of GPER1 correlated with over-expression of HER-2, EGFR (HER-1), and lymph node status. Surprisingly, GPER-1 was negatively correlated with relapse-free survival in patients that were treated with tamoxifen compared to those receiving aromatase inhibitors (20-23). Surprisingly, independent studies have shown that tamoxifen and $4-\mathrm{OH}$ tamoxifen (the main tamoxifen metabolite), two ER $\alpha$ antagonists, act as GPER-1 agonists $(17,22,24)$. Furthermore, GPER-1 expression seems to be a favorable factor for relapse-free survival, but only in patients that did not receive tamoxifen; consequently, loss of GPER-1 improves the prognosis in patients treated with tamoxifen indicating that GPER-1 might be related to tamoxifen resistance in breast cancer (25). Activation of GPER-1 by $4-\mathrm{OH}$ tamoxifen also increases the expression of connective tissue growth factor (CTGF), which may be related to a more aggressive behavior of some breast tumors (26).

In general, it is estimated that resistance mechanisms are related to mutations that arise within the intermediates that are part of the signaling pathways triggered by estradiol or its metabolites, promoting the survival and proliferation of tumor cells (27). Isolated models like those using tamoxifen-resistant MCF-7 cells (a cellular model that imitates therapeutic conditions), stimulated with estradiol point to an overexpression of GPER-1 (20). These observations showed that tamoxifen could act as non-specific GPER-1 agonist increasing breast cancer cells proliferation and migration. Moreover, it has recently been reported that patients with GPER-1-positive breast tumors, after four to six months of treatment with tamoxifen, not only generated resistance to therapy, but also suffered an increase in the size of tumor mass (28).

The current experiments were designed to examine the protein levels of GPER-1 in ER $\alpha$-positive breast cancer cells that were continuously treated with tamoxifen for a period of 7 days and to investigate the mobilization of intracellular $\mathrm{Ca}^{2+}$ and cell proliferation that follows their stimulation with tamoxifen or GPER-1 agonists. We also investigated the protein levels of classical ER $\alpha$ and kinin B1 receptor (B1R), another GPCR associated to breast cancer progression $(6,29)$.

\section{MATERIALS AND METHODS}

\section{Cell Culture}

MCF-7 cells, an estrogen-sensitive or ER $\alpha$-positive/GPER-1positive breast cancer cell line was used for all experiments. The MCF-7 cell line was obtained from the American Type Culture Collection (Manassas, VA USA). Cells were grown in modified Eagle's Dulbecco (DMEM) supplemented with 10\% fetal bovine serum (FBS), $2 \mathrm{mM}$ glutamine and penicillinstreptomycin (10,000 U/ml sodium penicillin $\mathrm{G}$ and 10,000 $\mu \mathrm{g}$ / $\mathrm{ml}$ streptomycin sulfate; GIBCO BRL, Life Technologies) and $250 \mu \mathrm{g} / \mathrm{ml}$ fungizone. Cells were cultured at $37^{\circ} \mathrm{C}$ in a humidified incubator under $5 \% \mathrm{CO}_{2}$ and $95 \%$ air $(6,29)$.

\section{Prolonged Exposure of Breast Cancer Cells to Tamoxifen}

MCF-7 cells were grown and expanded for 7 days as mentioned above, in the presence of 1,000 nM tamoxifen (Sigma-Aldrich, USA). Medium containing tamoxifen was replaced every $48 \mathrm{~h}$. After 7 days of exposure to tamoxifen, cells were frozen in cell 
culture freezing medium containing dimethyl sulfoxide (GIBCO BRL, Life Technologies) and stored until used. When required, these cells were grown again in a medium containing 1,000 nM tamoxifen (24). In parallel experiments, control cells that were not treated with the drug were grown as described above. Once a confluence of $80 \%$ was reached, both tamoxifen-treated and untreated cells were maintained for $24 \mathrm{~h}$ in culture medium without phenol red, and FBS. Once synchronized, tamoxifentreated and untreated control cells were stimulated with 1,000 $\mathrm{nM}$ tamoxifen for 24,48 , and/or $72 \mathrm{~h}$.

\section{Western Blotting}

Cells were homogenized with cold RIPA buffer ( $5 \mathrm{mM}$ Tris- $\mathrm{HCl}$ $\mathrm{pH} 7.4$ containing $1 \mathrm{mM}$ EDTA, $10 \mu \mathrm{g} / \mathrm{ml}$ aprotinin, $1 \mathrm{mM}$ phenylmethane-sulphonyl fluoride, $1 \mu \mathrm{g} / \mathrm{ml}$ leupeptin, and 10 $\mu \mathrm{g} / \mathrm{ml}$ pepstatin). Proteins were separated by sodium dodecyl sulphate-polyacrylamide gel electrophoresis (SDS-PAGE) and transferred onto Immobilon-P membranes (Millipore, Billerica, MA USA). Membranes were incubated with primary antibodies for $2 \mathrm{~h}$ and then with the corresponding peroxidase-labeled secondary antibody for $30 \mathrm{~min}$. Peroxidase activity was visualized using a commercial chemiluminescence kit (Pierce, Rockford, USA). Anti-GPER-1 is a rabbit polyclonal antibody directed to the C-terminus of the human receptor (ab39742; Abcam, UK). Furthermore, antibodies raised against ER $\alpha$ (PA516440; Invitrogen, USA) and the kinin B1R (6) were used. The antibodies used for the first immunodetection procedure were stripped off as previously described (6) and glyceraldehyde 3phosphate dehydrogenase (GAPDH, Millipore) was then detected as control of protein loading.

\section{Measurement of the $\left[\mathrm{Ca}^{2+}\right]_{i}$}

Cells were grown and synchronized in medium without phenol red, FBS and antibiotics for $48 \mathrm{~h}$. Then, they were gently trypsinized, washed with PBS and incubated for $30 \mathrm{~min}$ at $37^{\circ} \mathrm{C}$ at a concentration of $5 \times 10^{6} \mathrm{cells} / \mathrm{ml}$, in the darkness with $5 \mathrm{mM}$ Indo-1 AM, a ratiometric fluorescent probe (Life Technologies). Next, cells were washed with PBS, resuspended in $25 \mathrm{mM}$ Hepes buffer pH 7.4 containing (125 mM NaCl, $5 \mathrm{mM}$ $\mathrm{KCl}, 1 \mathrm{mM} \mathrm{CaCl}_{2}, 0.5 \mathrm{mM} \mathrm{MgCl}_{2}, 1 \mathrm{mM} \mathrm{NaH}_{2} \mathrm{PO} 4,0.1 \%$ bovine serum albumin and $0.1 \%$ glucose $)(6,30)$. During the assay, cells were stimulated with $100 \mathrm{nM} \mathrm{ATP}$, which was used as a positive control. Additional controls were performed by using the anionic detergent triton X-100 and the calcium-chelating agent, EGTA (Figure 3C). Following stimulation with ATP, cells were stimulated with a range of concentrations of $17 \beta$-estradiol (0.1, 1 and $10 \mathrm{nM}$ ) (Sigma-Aldrich, Germany) or G1, the synthetic GPER-1 agonist (1, 10 and $100 \mathrm{nM}$ ) (Tocris, USA). Additionally, cells were pretreated for $5 \mathrm{~min}$ with an excess $(1,000 \mathrm{nM})$ of the GPER-1 antagonist, G15 (Tocris, USA) prior stimulation with $17 \beta$-estradiol or G1. Both, cells under prolonged treatment with tamoxifen (tamoxifen-treated cells) and untreated cells were stimulated with $10 \mathrm{nM} 17 \beta$-estradiol, $100 \mathrm{nM}$ G1 or $1,000 \mathrm{nM}$ tamoxifen. Tamoxifen was dissolved in ethanol and the other drugs were solubilized in dimethyl sulfoxide (SigmaAldrich, Germany).
Measurements were carried out in a spectrofluorometer LS55 (Perkin Elmer, Wellesley, MA USA) using $2 \times 10^{5}$ cells $/ \mathrm{ml}$ in a thermostated cuvette that was under continuous agitation. Measurements were performed using an excitation wavelength of $330 \mathrm{~nm}$, and emissions of $405 \mathrm{~nm}$ and $480 \mathrm{~nm}$ were recorded. Data were expressed using the ratiometric relationship between the absorbance at 405 and $480 \mathrm{~nm}$ (30).

\section{Cell Proliferation Assay}

Cells were seeded on 96-well plates and cultured at $70 \%$ subconfluence. After synchronization for $48 \mathrm{~h}$ in phenol redfree DMEM without FBS (6), cells were stimulated with a range of concentrations of tamoxifen $(50,100,500,1,000$, and 2,000 $\mathrm{nM}$ ). Comparative experiments were performed on cells stimulated, under identical conditions, but following pretreatment with the GPER-1 antagonist G15. After $24 \mathrm{~h}$ under stimulation, cells were pulsed with 5-bromo-2'deoxyuridine $(\mathrm{BrdU})$ for $2 \mathrm{~h}$. Incorporation of BrdU was determined by a colorimetric immunoassay according to manufacturer's protocol (Roche, Germany). At least three independent experiments were carried out for each concentration point and each point was performed in triplicates. Positive control experiments were carried out stimulating cells with $10 \%$ FBS.

\section{Statistical Analysis}

Statistical evaluation between experimental groups was done with ANOVA analysis followed by post-test pairwise comparisons using Tukey's test. Values were expressed as mean \pm SEM and significance was considered acceptable at the $5 \%$ level $(\mathrm{P}<0.05)$.

\section{RESULTS}

\section{Prolonged Tamoxifen Treatment Induces GPER-1 Overexpression and Increases Breast Cancer Cells Proliferation Rate}

It has been shown that use of tamoxifen on patients with initial GPER-1 positive breast tumors increases GPER-1 protein expression and markedly reduces patient survival (20). Here we have corroborated that GPER- 1 is overexpressed in breast cancer cells exposed for 7 days to 1,000 $\mathrm{nM}$ tamoxifen (Figure 1A), a concentration similar to that found in breast tissue of patients treated with this drug (24). When untreated cells and those under continuous treatment with tamoxifen were challenged with $1,000 \mathrm{nM}$ tamoxifen for 24,48 , or $72 \mathrm{~h}$, a significant increase in the expression of GPER-1 was observed in the cells under continuous treatment with the drug (Figure 1A). Furthermore, the proliferation rate, assessed as BrdU incorporation, in the cells that were under prolonged treatment with tamoxifen was significantly higher than those that were not under treatment (Figure 1B). A concentration-dependent response was clearly observed when the cells under prolonged treatment were stimulated with tamoxifen ranging 50 to 2,000 $\mathrm{nM}$ (Figure 1B). By comparison, cells that were not under continuous treatment with tamoxifen showed an increase in 

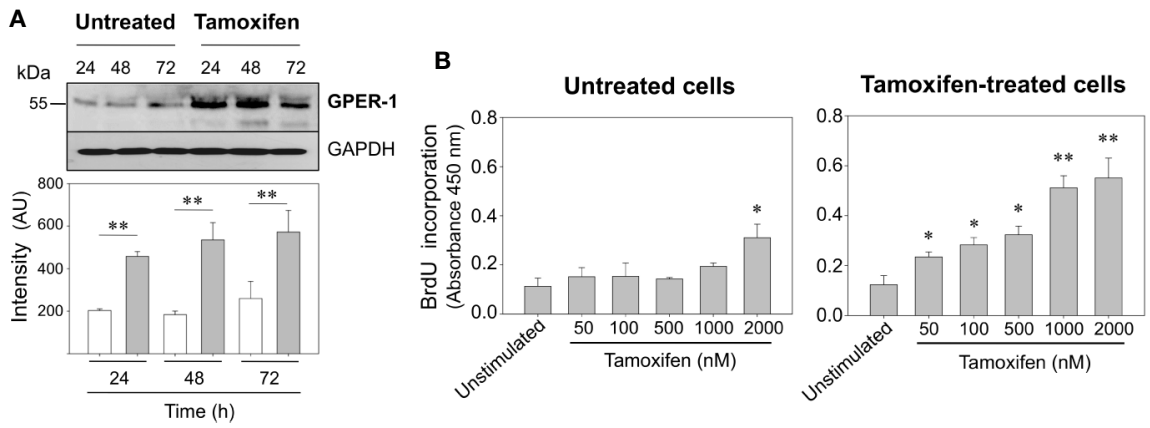

FIGURE 1 Continuous tamoxifen treatment induces GPER-1 overexpression and an increase in BrdU incorporation in response to stimulation with tamoxifen. (A) MCF-7 cells that were under treatment with tamoxifen for 7 days together with their respective untreated controls were cultured, synchronized and then stimulated with 1,000 nM tamoxifen for 24, 48 and $72 \mathrm{~h}$. Cells were homogenized and proteins separated by SDS-PAGE, transferred onto Immobilon-P membranes and immunoblotted using a specific antibody for GPER-1. The antibody was stripped off and the same membrane incubated with anti-GAPDH antibody as loading control. Data are representative of two independent experiments $(n=2)$. ${ }^{* *} P<0.001$. (B) Untreated cells or continuously exposed to tamoxifen were grown on 96 well plates, synchronized and stimulated with various concentrations of tamoxifen for $24 \mathrm{~h}$. BrdU incorporation was determined by a colorimetric cell proliferation immunoassay and measuring absorbance at $450 \mathrm{~nm}$. Results are shown as mean $\pm \mathrm{SEM}(\mathrm{n}=3){ }^{*} \mathrm{P}<0.05$; ${ }^{\star \star} \mathrm{P}<0.001$ between stimulated and unstimulated cells in both tamoxifen-treated and untreated cells.

BrdU incorporation only when they were stimulated with 2,000 nM tamoxifen (Figure 1B).

\section{Prolonged Tamoxifen Treatment Increases Intracellular Calcium Signaling in Breast Cancer Cells Challenged With Tamoxifen}

To examine whether continuous tamoxifen exposure modifies intracellular calcium signaling, cells were synchronized before labeling with the Indo-1 AM probe. Following a pulse with 1,000 $\mathrm{nM}$ tamoxifen, a significant $\left[\mathrm{Ca}^{2+}\right]_{i}$ mobilization was generated in cells under prolonged tamoxifen treatment when compared with those that were not under prolonged treatment; in the latter, $\left[\mathrm{Ca}^{2+}\right]_{i}$ mobilization was almost negligible (Figure 2). Cell integrity was assessed by stimulation of the same cells with a pulse of $100 \mathrm{nM}$ ATP (Figure 2, top inbox). This response was comparable to that obtained in cells that were not under prolonged treatment with tamoxifen and were also stimulated with $100 \mathrm{nM} \mathrm{ATP}$ (not shown). Further controls of the technique included addition of triton X-100 and EGTA. Interestingly, preincubation of cells continuously treated with tamoxifen, for 5 min with 1,000 nM G15 (GPER-1 antagonist) significantly reduced the $\left[\mathrm{Ca}^{2+}\right]_{i}$ mobilization triggered by tamoxifen in these cells, suggesting that an important fraction of the response to tamoxifen may be due to GPER-1 activation (Figure 2, bottom inbox).

\section{Breast Cancer Cells Continuously Exposed to Tamoxifen Display Higher $\left[\mathrm{Ca}^{2+}\right]_{i}$ Mobilization Than Untreated Cells When Stimulated With Estrogen or G1}

To examine the influence of ER $\alpha$ and GPER-1 in calcium signaling of breast cancer cells, several approaches were carried out. These experiments showed that cells continuously treated with tamoxifen exhibited higher $\left[\mathrm{Ca}^{2+}\right]_{i}$ mobilization than untreated cells when they were stimulated with $10 \mathrm{nM} 17 \beta$ estradiol or $100 \mathrm{nM} \mathrm{G1}$, a specific GPER-1 agonist (Figures 3A, B). The increase in $\left[\mathrm{Ca}^{2+}\right]_{i}$ mobilization in response to $17 \beta$ estradiol was approximately $50 \%$ greater than that produced by the cells which had not been under prolonged treatment with tamoxifen; by comparison the increase produced by G1 was approximately $25 \%$ higher than that observed in untreated cells (Figures 3A, B). Preincubation of continuously treated cells with 1,000 nM G15, a GPER-1 antagonist, blunted the response triggered by G1 (Figure 3C). Interestingly, the same antagonist significantly reduced the response generated by $17 \beta$-estradiol. Additional controls were performed by using the anionic detergent triton X-100 and the calcium-chelating agent EGTA (Figure 3C). These results suggest that the increase in $\left[\mathrm{Ca}^{2+}\right]_{i}$ mobilization, triggered by G1 or $17 \beta$-estradiol in tamoxifentreated cells, is mediated mainly by GPER-1.

\section{Prolonged Tamoxifen Treatment Increases the Proliferation Rate of Breast Cancer Cells in Response to Estrogen, G1, and Tamoxifen}

To examine whether prolonged exposition of breast cancer cells to tamoxifen increases the cycling activity of these cells, a proliferation assay based on the incorporation of BrdU, an analogue of thymidine was performed. An increase in the incorporation of $\mathrm{BrdU}$ was observed in untreated and continuously treated cells stimulated for $24 \mathrm{~h}$ with $10 \mathrm{nM} 17 \beta$ estradiol and $100 \mathrm{nM} \mathrm{G1}$ (Figure 4). This increase was also significant when cells were stimulated with 2,000 nM tamoxifen (Figure 4). Interestingly, the increase in BrdU incorporation observed following stimulation with tamoxifen was inhibited by pretreatment of both continuously treated and untreated cells with G15, the GPER-1 antagonist (Figures 4A, B). 

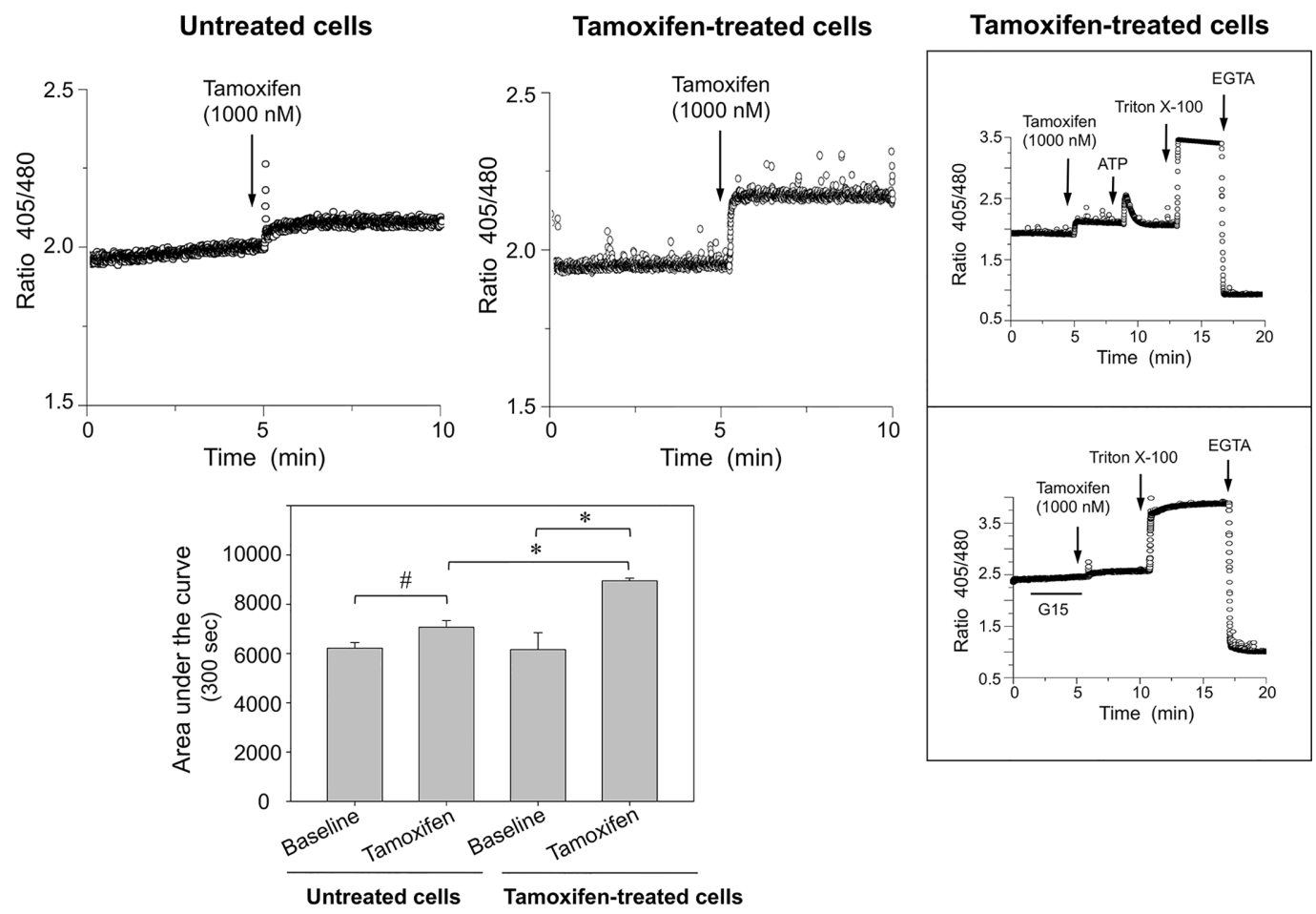

FIGURE 2 | Breast cancer cells continuously exposed to tamoxifen display higher $\left[\mathrm{Ca}^{2+}\right]_{i}$ mobilization than untreated controls following stimulation with tamoxifen. MCF-7 cells that were under prolonged treatment with tamoxifen for 7 days, together with their respective untreated controls, were cultured, detached, and loaded with Indo-AM calcium probe and stimulated with 1,000 nM tamoxifen. The area under the curve was estimated to assess the magnitude of the response in both conditions. Results are shown as mean \pm SEM $(n=3) ;{ }^{*} P<0.05$; ${ }^{*}$ Not significant. Insert: The response elicited by tamoxifen was inhibited by preincubation of cells for 5 min with 1,000 nM G15, a GPER-1 antagonist. Additional controls using ATP, triton X-100 and EGTA are also shown.

\section{Prolonged Tamoxifen Treatment Overexpresses the Kinin B1 Receptor but Not ER $\alpha$ in Breast Cancer Cells}

Finally, we addressed two crucial questions: the first one was whether the treatment of MCF-7 cells with $1,000 \mathrm{nM}$ tamoxifen for 7 days modified the expression levels of the classical estrogen receptor, ER $\alpha$. As expected, protein expression levels of ER $\alpha$ did not change in tamoxifentreated breast cancer cells respect to the untreated cells (Figure 5A). The second question was to examine the expression levels of another GPCR already known to favor the malignant phenotype of $\mathrm{ER} \alpha$ positive breast cancer cells. Our previous studies have shown that stimulation of the kinin $\mathrm{B} 1 \mathrm{R}$ results in an increase in cell proliferation, chemotaxis and release of matrix metalloproteases 2 and 9 from breast cancer cells $(6,29)$. Unexpectedly, kinin B1R protein expression was dramatically increased in the continuously treated cells that were additionally stimulated with 2,000 nM tamoxifen for 24, 48, and $72 \mathrm{~h}$ (Figure 5B), an effect that reinforces our first observations that kinin B1R stimulation increases the proliferation of breast cancer cells even at higher levels than estrogen (6). Our results suggest that ER $\alpha$ would not be directly involved in pharmacological resistance.

\section{DISCUSSION}

Estrogens, predominantly $17 \beta$-estradiol and its classical receptor, $\mathrm{ER} \alpha$, contribute to the development and progression of breast cancer. Drugs that block estrogen production or signaling by binding to ER $\alpha$ have been successfully used for many years. Such therapy includes SERMs (e.g., tamoxifen, raloxifene), antagonists of ER $\alpha$ (e.g., fulvestrant) and aromatase inhibitors, including reversible non-steroidal agents (e.g., letrozole, anastrozole), among others. Tamoxifen is, so far, one of the most commonly antiestrogenic drugs used for breast cancer treatment $(31,32)$. Endocrine therapy, based on the use of tamoxifen, has predominantly antiestrogenic effects in the breast and is aimed to block ER $\alpha$ in estrogen-sensitive breast cancer. Nevertheless, breast cancer patients may acquire resistance to antiestrogenic drugs complicating treatment. On the other hand, the existence of more complex and undiscovered signaling pathways beyond estrogen receptors appears to control cancer progression (33, 34). Thereby, the use of tamoxifen on breast cancer patients with initial GPER-1 positive tumors increased GPER-1 protein expression and markedly reduced survival (20).

The MCF-7 breast cancer cell line has emerged as one of the most widely used tool to scrutinize the effects of estrogen, SERMs 

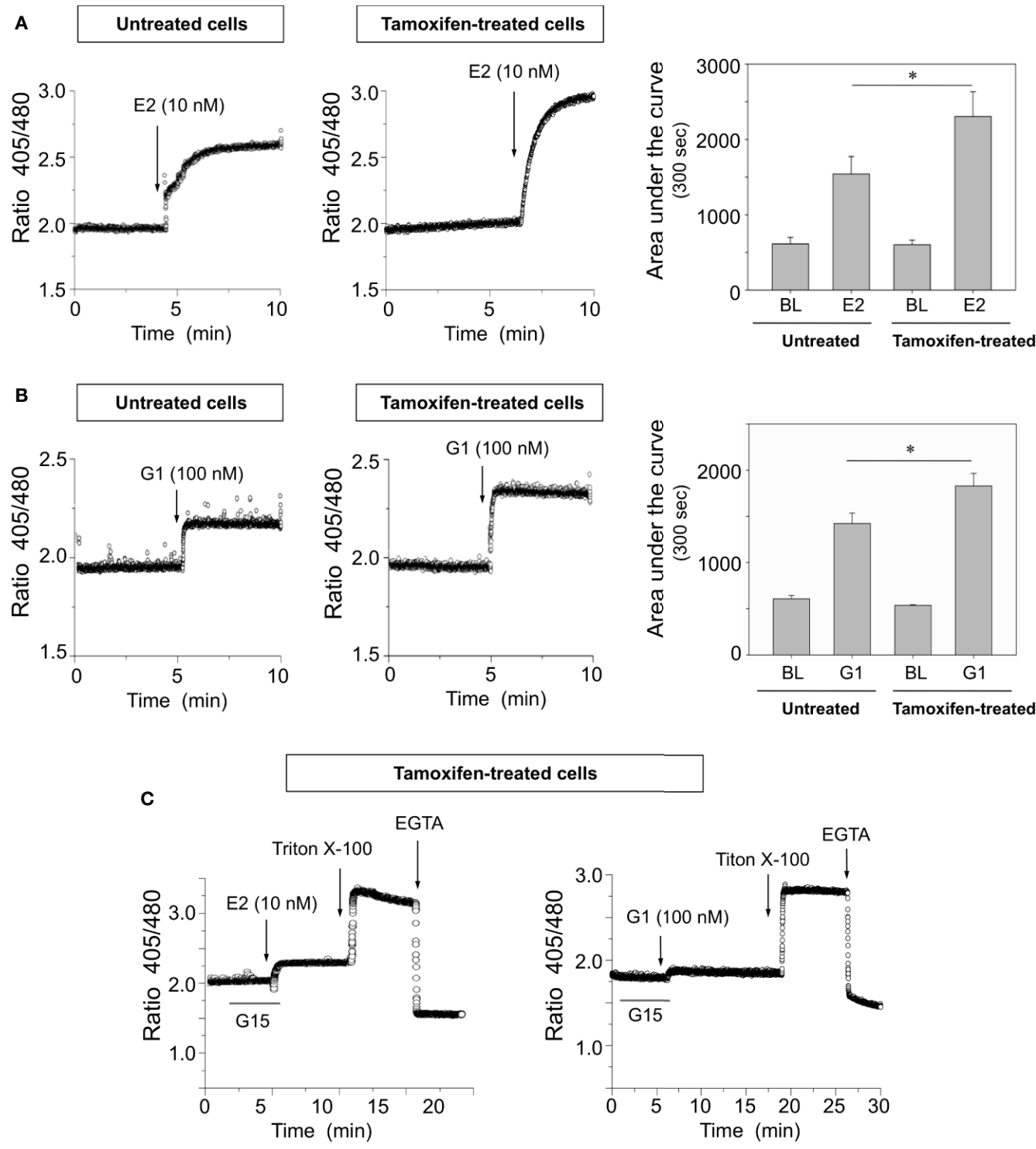

FIGURE 3 | Breast cancer cells continuously exposed to tamoxifen exhibit higher $\left[\mathrm{Ca}^{2+}\right]_{j}$ mobilization than untreated controls when are stimulated with $17 \beta$-estradiol or G1. Continuously treated and untreated MCF-7 cells were cultured, detached and loaded with Indo-AM calcium probe before stimulation with 10 nM $17 \beta$-estradiol (E2) (A) or 100 nM G1 (B), a specific synthetic agonist of GPER-1. The area under the curve was calculated and graphed to assess the magnitude of the response in each condition. BL, baseline. (C) Preincubation for 5 min with 1,000 nM G15 significantly decreased [Ca $\left.{ }^{2+}\right]_{i}$ mobilization in tamoxifen-treated cells; additional controls using triton X-100 and EGTA are also depicted. Results are shown as mean \pm SEM $(n=3){ }^{*} P<0.05$; between tamoxifen-treated cells and untreated controls.

and ER $\alpha$ antagonists. Although we cannot fully extrapolate the results obtained in vitro to the patients, this cell line is a good example of those mammary tumors made up of cells that express both ER $\alpha$ and GPER-1. Similarly, MCF-7 cells have been used to investigate the resistance to antiestrogenic drugs such as tamoxifen. Clearly, these studies should be expanded to other ER $\alpha$ positive breast cancer cell lines such as T47D and ZR-75-1 cells or better yet to $3 \mathrm{D}$ cultures using different cell lines or tumor cells directly obtained from patients with ER $\alpha$ positive breast tumors. Our experiments showed that MCF-7 cells exposed for $24 \mathrm{~h}$ to various concentrations of tamoxifen increased $\mathrm{BrdU}$ incorporation
(DNA synthesis) when tamoxifen was present at 2,000 nM. A similar observation had been reported in the late eighties by Wakeling et al. (35), using also MCF-7 cells. Furthermore, Reddel and Sutherland (36) found that $10 \mathrm{nM}$ tamoxifen had a proliferative effect on T47D breast cancer cells, a cell line which like MCF-7 cells expresses both ER $\alpha$ and GPER-1. Moreover, almost 50 years ago, tamoxifen had already been blamed to increase the growth of some types of breast cancer $(37,38)$. Interestingly, tamoxifen and $4-\mathrm{OH}$ tamoxifen (the main metabolite of tamoxifen), two compounds that antagonize estrogen binding to ER $\alpha$, are GPER-1 agonists $(8,17,39)$. In a 

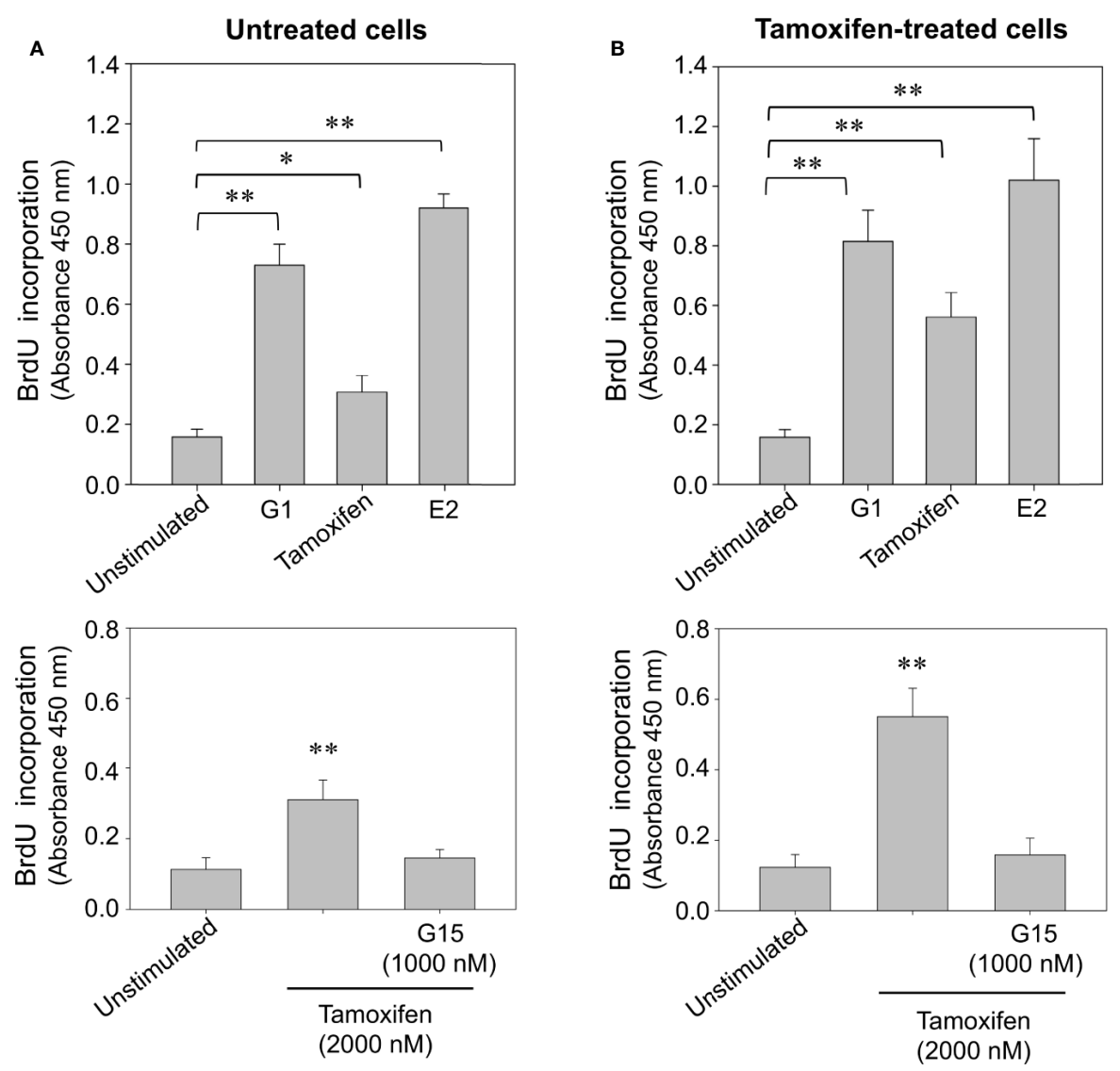

FIGURE 4 | Continuous tamoxifen treatment induces an increase in BrdU incorporation in breast cancer cells stimulated with tamoxifen. Untreated cells (A) or continuously exposed to tamoxifen (B) were grown on 96-well plates, synchronized and stimulated with 2,000 $\mathrm{nM}$ tamoxifen, $10 \mathrm{nM} 17 \beta$-estradiol (E2) or $100 \mathrm{nM}$ G1 for $24 \mathrm{~h}$. BrdU incorporation was determined by a cell proliferation immunoassay and by measuring absorbance at $450 \mathrm{~nm}$. The effect produced by tamoxifen on BrdU incorporation was significantly reduced by preincubation of cells with 1,000 nM G15 in both, untreated cells and cells continuously exposed to the drug. Results are shown as mean \pm SEM $(n=3){ }^{*} \mathrm{P}<0.05$; ${ }^{\star \star} \mathrm{P}<0.001$ versus unstimulated cells or preincubated with $\mathrm{G} 15$.
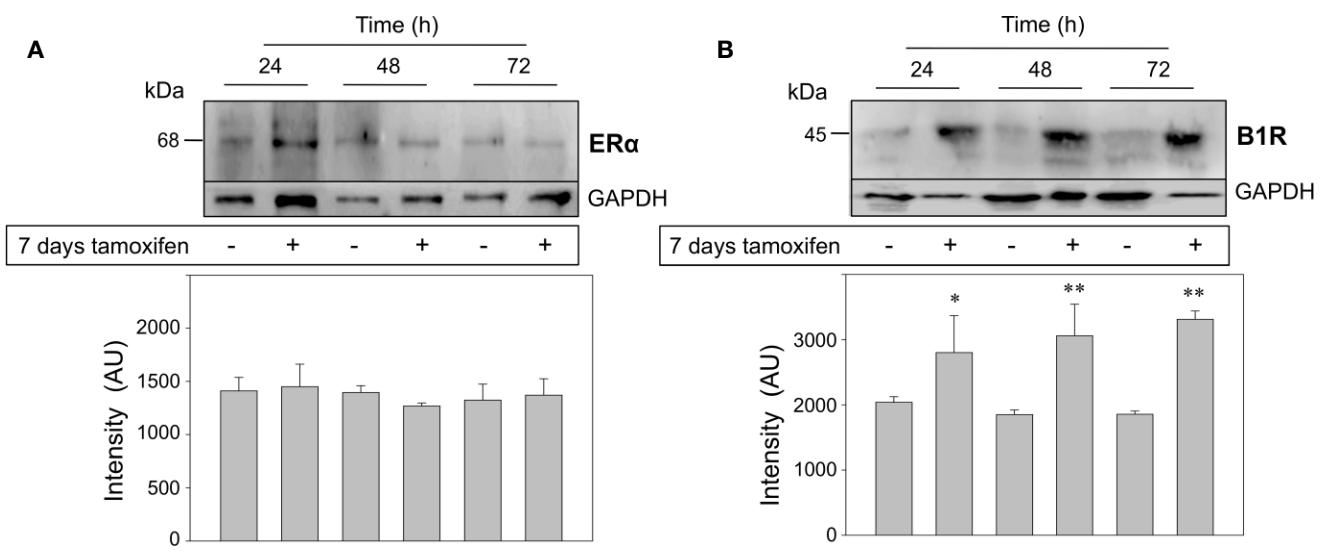

FIGURE 5 | Breast cancer cells continuously treated with tamoxifen overexpress the kinin B1R, but not ER $\alpha$. MCF-7 cells that were under treatment with tamoxifen for 7 days together with their respective untreated controls were stimulated with 1,000 nM tamoxifen by 24, 48, and $72 \mathrm{~h}$. Cell proteins were separated by SDSPAGE, transferred onto Immobilon-P and immunoblotted with antibodies for detection of $E R \alpha(A)$ and kinin B1R (B). Antibodies were stripped off and the same membranes were incubated with an antibody directed to GAPDH as control for protein loading. Data are representative of two independent experiments $(\mathrm{n}=2) .{ }^{*} \mathrm{P}<$ $0.05 ;{ }^{* *} \mathrm{P}<0.001$ between tamoxifen-treated and untreated cells. 
series of seminal experiments, Thomas et al. (13) were the first to describe a competitive binding ( $K_{\mathrm{i}}$ values in the $10^{-7} \mathrm{M}$ range) between estrogen and tamoxifen for GPER-1 expressed by SKBr3 breast cancer cells (ER $\alpha$ and ER $\beta$ negative, GPER-1 positive) or expressed by HEK cells transfected with GPER-1. Moreover, tamoxifen binding to GPER-1 resulted in activation of a stimulatory $G$ protein and increase in adenylyl cyclase activity and cAMP levels. Subsequent experiments have shown that agonistic activity of tamoxifen or $4 \mathrm{OH}$-tamoxifen triggers signaling pathways such as PI3K, ERK1/2 MAPK, and EGFR transactivation (14). The EGFR/ERK1/2 signaling cascade upregulates the expression of Egr-1 that in turn participates in the transcription of CTGF and cyclin D1, two genes that regulate breast cancer growth $(16,40)$. Similarly, agonistic activity of tamoxifen increases the proliferation of endometrial cancer cells by activating the GPER-1/EGFR/ERK1/2/CyclinD1 route, data that is in agreement with the observation that endometrial cancer patients under tamoxifen treatment exhibit a worse prognosis (41).

Previous reports have shown an increased translocation of GPER-1 to the cell surface of MCF-7 breast cancer cells that were continuously exposed to $10 \mathrm{nM}$ tamoxifen for 6 months and stimulated with $17 \beta$-estradiol (20). Furthermore, other studies indicate that concentrations of tamoxifen and 4-OH tamoxifen reached in breast tissue of patients with $\mathrm{ER} \alpha$-positive breast cancer are significantly higher (up to about 100 times) than those present in plasma (42). Our results show that treatment of MCF-7 cells with $1,000 \mathrm{nM}$ tamoxifen for 7 days produces a significant increase of GPER-1 protein expression. It is important to point out that this concentration is similar to that found in breast tissue of breast cancer patients treated with the drug (24). Other studies have shown that after 12 months of treatment with $10^{-7} \mathrm{M}$ tamoxifen, this drug no longer inhibits the proliferative effect of estrogen on MCF-7 cells; during this period of time, tamoxifen did not increase cell proliferation (43). Furthermore, long-term exposure to tamoxifen has been shown to increase aromatase expression and activity, effects that depend on GPER-1 activity (44). Our results indicate that a short period of 7 days under continuous treatment with 1,000 $\mathrm{nM}$ tamoxifen induces overexpression of GPER-1, making breast cancer cells more sensitive to tamoxifen, which following GPER-1 activation triggers DNA synthesis, an effect that can be blocked by a specific GPER-1 antagonist. Therefore, overexpression and activity of GPER-1 appear as crucial steps for tamoxifen resistance since tamoxifen could increase cell proliferation directly by stimulating GPER-1 or indirectly by rising estrogen levels as result of an increase in the activity and expression of aromatase.

GPER-1 overexpression could be associated to carcinogenesis and to molecular strategies developed by tumor cells to escape tamoxifen treatment. GPER-1 overexpression has been observed in invasive ductal carcinomas of the breast when compared to adjacent healthy tissue (23) and in inflammatory breast cancer, a more aggressive form of this neoplasia (45). Signaling through GPER-1 has been shown to trigger the expression of IL-1 $\beta$ and IL-1R1 in cancer-associated fibroblasts and breast cancer cells, respectively. Thus, coupling of IL1 $\beta$ secretion by cancer-associated fibroblasts to the expression of IL-1R1 by cancer cells, promotes a positive regulation of protumoral genes such as those for COX-2 and ATP-binding cassette super- family G member 2 (46). Yu et al., 2020 (47) reported that ER $\alpha$ positive metastatic tissue shows increased levels of GPER-1 and ATPbinding cassette super-family $\mathrm{G}$ member 2 genes, which have been involved with multiresistance to different types of chemotherapy. Additionally, treatment of tamoxifen-resistant MCF-7 cells with G1 or with Fulvestrant (ICI 182,780) significantly increased GPER-1 expression, when compared to non-resistant MCF-7 cells (47). Pharmacological therapies can also alter intracellular signaling cascades such as $\left[\mathrm{Ca}^{2+}\right]_{i}$ signaling, a key pathway in which calcium itself acts as second messenger or may participate in signal transduction to open ion channels. However, few studies have addressed the release of intracellular calcium triggered by tamoxifen in breast cancer cells. Our experiments showed that after prolonged treatment with tamoxifen, breast cancer cells stimulated with $1,000 \mathrm{nM}$ tamoxifen mobilized $\left[\mathrm{Ca}^{2+}\right]_{i}$ whereas untreated cells did not generate such a response. This response is a result of GPER-1 overexpression attributed to the prolonged treatment of breast cancer cells with the drug. In fact, preincubation of tamoxifen-treated cells with $1,000 \mathrm{nM}$ G15 reduced $\left[\mathrm{Ca}^{2+}\right]_{i}$ to basal levels. Interestingly, $\left[\mathrm{Ca}^{2+}\right]_{i}$ was also increased when continuously treated cells were stimulated with $10 \mathrm{nM} 17 \beta$-estradiol, an effect that was greatly reduced following preincubation of cells with the GPER-1 antagonist suggesting that GPER-1 may also be involved in this response. GPER-1 overexpression was further manifested when continuously treated cells were stimulated with $100 \mathrm{nM} \mathrm{G1}$, a synthetic GPER-1 agonist that also increased $\left[\mathrm{Ca}^{2+}\right]_{i}$ in these cells.

Relevance of $\left[\mathrm{Ca}^{2+}\right]_{i}$ mobilization in breast cancer cells has recently been adressed by Ji et al. (48) who showed that Cav1.3 (a subunit of the L-type calcium channel) is widely expressed in breast cancer tissue and is upregulated by estrogen. Notably, silencing of GPER-1 inhibited the positive regulation of Cav1.3 induced by estrogen, reversing the increase in intracellular calcium release and proliferation of breast cancer cells. Our experiments indicate that breast cancer cells continuously treated with tamoxifen exhibited a concentration-dependent increase in BrdU incorporation after stimulation with various concentrations of tamoxifen. As expected, preincubation of cells with 1,000 nM G15 reduced the BrdU incorporation induced by tamoxifen. Although the mechanisms of resistance in estrogen-sensitive breast cancer are probably multifactorial, our evidence indicates that at least part of the phenomenon may be due to overexpression and activation of GPER-1. This observation may be of great relevance for breast cancer patients that suffer from breast tumors that co-express GPER-1 and ER $\alpha$ and undergo tamoxifen treatment.

GPCRs are preponderant for tumor development, progression and generation of drug resistance (32). Therefore, we explored the possibility of molecular interactions between GPER-1 and the kinin B1R, another member of the GPCR family, which is strongly expressed in ER $\alpha$ positive breast cancer cells. We have previously shown that kinin B1R favors the malignant phenotype of breast cancer cells (MCF-7, T47D, and ZR-75-1 cells) because its stimulation by $\mathrm{B} 1 \mathrm{R}$ agonists induces cell proliferation and secretion of metalloproteinases-2 and -9 , and of kallikrein-related peptidase 6 , among other effects $(6,29,49)$. Coincidently, kinin B1R agonists are at higher levels in serum of patients with breast cancer than in healthy subjects (50), an observation that matched the 
presence of kinin B1R binding sites detected by our group in fibroadenomas, ductal carcinomas in situ and in invasive ductal carcinomas (6). Furthermore, the use of inhibitors has shown that metalloproteinases secretion and proliferation of breast cancer cells relies on EGFR transactivation and activation of the EGFR/ERK1/2 MAPK cascade $(6,28)$.

Interestingly, we observed B1R overexpression in breast cancer cells that were under exposure to tamoxifen for a 7-day period. Our data suggest that kinin B1R overexpression is an early event and that together with GPER-1 it may be part of a cross-talk network in estrogen-sensitive breast cancer cells to enhance cell proliferation and/or metastasis by activating signaling mechanisms, which are independent of ER $\alpha$. Analysis of data from a subset of breast cancer patients has shown that GPER-1 expression has also been positively correlated with overexpression of EGFR (21). Since, a cooperative effect or association between GPER-1 and kinin B1R in breast cancer has not been explored yet; a next set of experiments should be focused on the role of both receptors in breast cancer patients. In addition, the GPER-1/EGFR signaling axis mediates the expression of cell cycle regulatory genes in cancer-associated fibroblasts derived from breast cancer patients, favoring tumor progression (40). It has recently been shown that stimulation with tamoxifen, activates GPER-1, improving breast cancer stem cells viability and stemness and BAD phosphorylation, event that seems to be an alternative survival mechanism for these cells (51).

Together our findings suggest that GPER-1 plays a key role in the mechanisms of tamoxifen resistance of estrogen-sensitive breast cancer cells, extending the limits of understanding of the effects generated by tamoxifen in these cells.

\section{REFERENCES}

1. Liu Y, Ma H, Yao J. ER $\alpha$, a key target for cancer therapy: A review. Oncol Targets Ther (2020) 13:2183-91. doi: 10.2147/OTT.S236532

2. Luo J, Liu D. Does GPER really function as a G protein-coupled estrogen receptor in vivo? Front Endocrinol (Lausanne) (2020) 11:148. doi: 10.3389/ fendo.2020.00148

3. Musgrove EA, Sutherland RL. Biological determinants of endocrine resistance in breast cancer. Nat Rev Cancer (2009) 9:631-43. doi: 10.1038/nrc2713

4. Szego CM, Davis JS. Adenosine 3',5'-monophosphate in rat uterus: acute elevation by estrogen. Proc Natl Acad Sci U S A (1967) 58:1711-8. doi: 10.1073/pnas.58.4.1711

5. Merlin JL, Harlé A, Lion M, Ramacci C, Leroux A. Expression and activation of P38 MAP kinase in invasive ductal breast cancers: Correlation with expression of the estrogen receptor, HER2 and downstream signaling phosphorylated proteins. Oncol Rep (2013) 30:1943-8. doi: 10.3892/ or.2013.2645

6. Molina L, Matus CE, Astroza A, Pavicic F, Tapia E, Toledo C, et al. Stimulation of the bradykinin B1 receptor induces the proliferation of estrogen-sensitive breast cancer cells and activates the ERK1/2 signaling pathway. Breast Cancer Res Treat (2009) 118:499-510. doi: 10.1007/s10549009-0314-4

7. Aihara M, Yamamoto S, Nishioka $\mathrm{H}$, Inoue $\mathrm{Y}$, Hamano $\mathrm{K}$, Oka $\mathrm{M}$, et al. Optimizing high-resolution melting analysis for the detection of mutations of GPR30/GPER-1 in breast cancer. Gene (2012) 501:118-26. doi: 10.1016/ j.gene.2012.04.029

8. Molina L, Figueroa CD, Bhoola KD, Ehrenfeld P. GPER-1/GPR30 a novel estrogen receptor sited in the cell membrane: therapeutic coupling to breast cancer. Expert Opin Ther Targets (2017) 21:755-66. doi: 10.1080/ 14728222.2017 .1350264

\section{DATA AVAILABILITY STATEMENT}

The raw data supporting the conclusions of this article will be made available by the authors, without undue reservation.

\section{AUTHOR CONTRIBUTIONS}

LM contributed to the design and execution of the experiments, writing, discussion, and revision of the article. PE and CF contributed to the experimental design, discussion, writing, and revision of the article. $\mathrm{FB}, \mathrm{AO}$, and IR contributed to the experimental procedures.

\section{FUNDING}

The authors wish to thank FONDECYT for grant 1201635 (PE) and Vicerrectoría de Investigación, Desarrollo y Creación Artistica from Universidad Austral de Chile and the Departamento de Ciencias Básicas, Facultad de Medicina y Ciencia, Universidad San Sebastián for its continuous support.

\section{ACKNOWLEDGMENTS}

We are very grateful to José Sarmiento for his valuable support with the calcium assays.

9. Prossnitz ER, Arterburn JB. International union of basic and clinical pharmacology. XCVII. G protein-coupled estrogen receptor and its pharmacologic modulators. Pharmacol Rev (2015) 67:505-40. doi: 10.1124/ pr.114.009712

10. Vo DKH, Hartig R, Weinert S, Haybaeck J, Nass N. G-protein-coupled estrogen receptor (GPER)-specific agonist G1 induces ER stress leading to cell death in MCF-7 cells. Biomolecules (2019) 9:1-21. doi: 10.3390/ biom 9090503

11. Prossnitz ER, Arterburn JB, Smith HO, Oprea TI, Sklar LA, Hathaway HJ. Estrogen signaling through the transmembrane $\mathrm{G}$ protein-coupled receptor GPR30. Annu Rev Physiol (2008) 70:165-90. doi: 10.1146/ annurev.physiol.70.113006.100518

12. Prossnitz ER, Barton M. The G-protein-coupled estrogen receptor GPER in health and disease. Nat Rev Endocrinol (2011) 7:715-26. doi: 10.1038/ nrendo.2011.122

13. Thomas P, Pang Y, Filardo EJ, Dong J. Identity of an estrogen membrane receptor coupled to a $\mathrm{G}$ protein in human breast cancer cells. Endocrinology (2005) 146:624-32. doi: 10.1210/en.2004-1064

14. Filardo EJ, Quinn JA, Raymond Frackelton A, Bland KI. Estrogen action via the G protein-coupled receptor, GPR30: Stimulation of adenylyl cyclase and cAMP-mediated attenuation of the epidermal growth factor receptor-toMAPK signaling axis. Mol Endocrinol (2002) 16:70-84. doi: 10.1210/ mend.16.1.0758

15. Filardo EJ, Thomas P. GPR30: A seven-transmembrane-spanning estrogen receptor that triggers EGF release. Trends Endocrinol Metab (2005) 16:362-7. doi: 10.1016/j.tem.2005.08.005

16. Quinn JA, Graeber CT, Frackelton AR, Kim M, Schwarzbauer JE, Filardo EJ. Coordinate regulation of estrogen-mediated fibronectin matrix assembly and epidermal growth factor receptor transactivation by the $G$ protein-coupled receptor, GPR30. Mol Endocrinol (2009) 23:1052-64. doi: 10.1210/me.20080262 
17. Pandey DP, Lappano R, Albanito L, Madeo A, Maggiolini M, Picard D. Estrogenic GPR30 signalling induces proliferation and migration of breast cancer cells through CTGF. EMBO J (2009) 28:523-32. doi: 10.1038/ emboj.2008.304

18. Haas E, Bhattacharya I, Brailoiu E, Damjanovi M, Cristina G, Gao X, et al. Regulatory Role of G Protein-Coupled Estrogen Receptor for Vascular Function and Obesity. Circ Res (2009) 104:288-91. doi: 10.1161/ CIRCRESAHA.108.190892

19. Henic E, Noskova V, Høyer-Hansen G, Hansson S, Casslén B. Estradiol attenuates EGF-induced rapid uPAR mobilization and cell migration via the G-protein-coupled receptor 30 in ovarian cancer cells. Int J Gynecol Cancer (2009) 19:214-22. doi: 10.1111/IGC.0b013e31819bcb75

20. Ignatov A, Ignatov T, Roessner A, Costa SD, Kalinski T. Role of GPR30 in the mechanisms of tamoxifen resistance in breast cancer MCF-7 cells. Breast Cancer Res Treat (2010) 123:87-96. doi: 10.1007/s10549-009-0624-6

21. Ignatov A, Ignatov T, Weienborn C, Eggemann H, Bischoff J, Semczuk A, et al. G-protein-coupled estrogen receptor GPR30 and tamoxifen resistance in breast cancer. Breast Cancer Res Treat (2011) 128:457-66. doi: 10.1007/ s10549-011-1584-1

22. Filardo EJ, Graeber CT, Quinn JA, Resnick MB, Giri D, DeLellis RA, et al. Distribution of GPR30, a seven membrane-spanning estrogen receptor, in primary breast cancer and its association with clinicopathologic determinants of tumor progression. Clin Cancer Res (2006) 12:6359-66. doi: 10.1158/10780432.CCR-06-0860

23. Zhou X, Lei Q, Guan K, Zhou X, Wang S, Wang Z, et al. Estrogen regulates Hippo signaling via GPER in breast cancer. J Clin Invest (2015) 125:2123-35. doi: 10.1172/JCI79573

24. Kisanga ER, Gjerde J, Guerrieri-Gonzaga A, Pigatto F, Pesci-Feltri A, Robertson C, et al. Tamoxifen and Metabolite Concentrations in Serum and Breast Cancer Tissue during Three Dose Regimens in a Randomized Preoperative Trial. Clin Cancer Res (2004) 10:2336-43. doi: 10.1158/10780432.CCR-03-0538

25. Ignatov T, Claus M, Nass N, Haybaeck J, Seifert B, Kalinski T, et al. Gprotein-coupled estrogen receptor GPER-1 expression in hormone receptor-positive breast cancer is associated with poor benefit of tamoxifen. Breast Cancer Res Treat (2019) 174:121-7. doi: 10.1007/ s10549-018-5064-8

26. Ren J, Guo H, Wu H, Tian T, Dong D, Zhang Y, et al. GPER in CAFs regulates hypoxia-driven breast cancer invasion in a CTGF-dependent manner. Oncol Rep (2015) 33:1929-37. doi: 10.3892/or.2015.3779

27. Hanahan D, Weinberg RA. Hallmarks of cancer: The next generation. Cell (2011) 144:646-74. doi: 10.1016/j.cell.2011.02.013

28. Ignatov T, Treeck O, Kalinski T, Ortmann O, Ignatov A. GPER-1 expression is associated with a decreased response rate to primary tamoxifen therapy of breast cancer patients. Arch Gynecol Obstet (2020) 301:565-71. doi: 10.1007/ s00404-019-05384-6

29. Ehrenfeld P, Conejeros I, Pavicic MF, Matus CE, Gonzalez CB, Quest AFG, et al. Activation of kinin B1 receptor increases the release of metalloproteases2 and -9 from both estrogen-sensitive and -insensitive breast cancer cells. Cancer Lett (2011) 301:106-18. doi: 10.1016/j.canlet.2010.09.020

30. Ehrenfeld P, Millan C, Matus CE, Figueroa JE, Burgos RA, Nualart F, et al. Activation of kinin $\mathrm{B} 1$ receptors induces chemotaxis of human neutrophils. J Leukoc Biol (2006) 80:117-24. doi: 10.1189/jlb.1205744

31. Lonard DM, Smith CL. Molecular perspectives on selective estrogen receptor modulators (SERMs ): progress in understanding their tissue-specific agonist and antagonist actions. Steroids (2002) 67:15-24. doi: 10.1016/S0039-128X (01)00133-7

32. Molina L, Bustamante FA, Bhoola KD, Figueroa CD, Ehrenfeld P. Possible role of phytoestrogens in breast cancer via GPER-1/GPR30 signaling. Clin Sci (2018) 132:2583-98. doi: 10.1042/CS20180885

33. Hsu LH, Chu NM, Lin YF, Kao SH. G-protein coupled estrogen receptor in breast cancer. Int J Mol Sci (2019) 20:306. doi: 10.3390/ijms20020306

34. Mosly D, Turnbull A, Sims A, Ward C, Langdon S. Predictive markers of endocrine response in breast cancer. World J Exp Med (2018) 30:1-11. doi: 10.5493/wjem.v8.i1.1

35. Wakeling AE, Newboult E, Peters SW. Effects of antioestrogens on the proliferation of MCF-7 human breast cancer cells. J Mol Endocrinol (1989) 2:225-34. doi: 10.1677/jme.0.0020225
36. Reddel RR, Sutherland RL. Tamoxifen stimulation of human breast cancer cell proliferation in vitro: a possible model for tamoxifen tumour flare. Eur Cancer Clin Oncol (1984) 20:1419-24. doi: 10.1016/0277-5379(84)90062-2

37. McIntosh IH, Thynne GS. Tumour stimulation by anti-oestrogens. Br J Surg (1977) 64:900-1. doi: 10.1002/bjs.1800641218

38. Plotkin D, Lechner JJ, Jung WE, Rosen PJ. Tamoxifen Flare in Advanced Breast Cancer. JAMA J Am Med Assoc (1978) 240:2644-6. doi: 10.1001/ jama.1978.03290240044022

39. Prossnitz ER, Arterburn JB, Smith HO, Oprea TI, Sklar LA, Hathaway HJ. Estrogen signaling through the transmembrane $G$ protein-coupled receptor GPR30. Annu Rev Physiol (2008) 70:165-90. doi: 10.1146/annurev.physiol. 70.113006.100518

40. Pisano A, Santolla MF, De Francesco EM, De Marco P, Rigiracciolo DC, Perri MG, et al. GPER, IGF-IR, and EGFR transduction signaling are involved in stimulatory effects of zinc in breast cancer cells and cancer-associated fibroblasts. Mol Carcinog (2017) 56:580-93. doi: 10.1002/mc.22518

41. Zhang L, Li Y, Lan L, Liu R, Wu Y, Qu Q, et al. Tamoxifen has a proliferative effect in endometrial carcinoma mediated via the GPER/EGFR/ERK/cyclin D1 pathway: A retrospective study and an in vitro study. Mol Cell Endocrinol (2016) 437:51-61. doi: 10.1016/j.mce.2016.08.011

42. Végvári Á, Shavkunov AS, Fehniger TE, Grabau D, Niméus E, Marko-Varga G. Localization of tamoxifen in human breast cancer tumors by MALDI mass spectrometry imaging. Clin Transl Med (2016) 5:10. doi: 10.1186/s40169-0160090-9

43. Fan P, Wang J, Santen RJ, Yue W. Long-term treatment with tamoxifen facilitates translocation of estrogen receptor $\alpha$ out of the nucleus and enhances its interaction with EGFR in MCF-7 breast cancer cells. Cancer Res (2007) 67:1352-60. doi: 10.1158/0008-5472.CAN-06-1020

44. Catalano S, Giordano C, Panza S, Chemi F, Bonofiglio D, Lanzino M, et al. Tamoxifen through GPER upregulates aromatase expression: A novel mechanism sustaining tamoxifen-resistant breast cancer cell growth. Breast Cancer Res Treat (2014) 146:273-85. doi: 10.1007/s10549-014-3017-4

45. Ohshiro K, Schwartz AM, Levine PH, Kumar R. Alternate estrogen receptors promote invasion of inflammatory breast cancer cells via non-genomic signaling. PloS One (2012) 7:e30725. doi: 10.1371/journal.pone.0030725

46. De Marco P, Lappano R, Francesco EM, De, Cirillo F, Pupo M, et al. GPER signalling in both cancer-associated fibroblasts and breast cancer cells mediates a feedforward IL1ß/IL1R1 response. Sci Rep (2016) 6:1-14. doi: $10.1038 /$ srep24354

47. Yu T, Cheng H, Ding Z, Wang Z, Zhou L, Zhao P, et al. GPER mediates decreased chemosensitivity via regulation of ABCG2 expression and localization in tamoxifen-resistant breast cancer cells. Mol Cell Endocrinol (2020) 506:110762. doi: 10.1016/j.mce.2020.110762

48. Ji Y, Han Z, Shao L, Zhao Y. Ultrasound-targeted microbubble destruction of calcium channel subunit $\alpha$ 1D siRNA inhibits breast cancer via G proteincoupled receptor 30. Oncol Rep (2016) 36:1886-92. doi: 10.3892/or.2016.5031

49. Ehrenfeld P, Manso L, Pavicic MF, Matus CE, Borquez C, Lizama A, et al. Bioregulation of kallikrein-related peptidases 6,10 and 11 by the Kinin b1 receptor in breast cancer cells. Anticancer Res (2014) 34:6925-38.

50. Villanueva J, Shaffer DR, Philip J, Chaparro CA, Erdjument-Bromage H, Olshen $\mathrm{AB}$, et al. Differential exoprotease activities confer tumor-specific serum peptidome patterns. J Clin Invest (2006) 116:271-84. doi: 10.1172/ JCI26022

51. Chan Y, Lai AC -Y, Lin R, Wang Y, Wang Y, Chang W, et al. GPER-induced signaling is essential for the survival of breast cancer stem cells. Int J Cancer (2020) 146:1674-85. doi: 10.1002/ijc.32588

Conflict of Interest: The authors declare that the research was conducted in the absence of any commercial or financial relationships that could be construed as a potential conflict of interest.

Copyright (c) 2020 Molina, Bustamante, Ortloff, Ramos, Ehrenfeld and Figueroa. This is an open-access article distributed under the terms of the Creative Commons Attribution License (CC BY). The use, distribution or reproduction in other forums is permitted, provided the original author(s) and the copyright owner(s) are credited and that the original publication in this journal is cited, in accordance with accepted academic practice. No use, distribution or reproduction is permitted which does not comply with these terms. 